$$
\text { CONF- } 9606208--4
$$

Title:

Los Alamos Pinhole Camera (LAPC): A New Flexible X-Ray Pinhole Camera

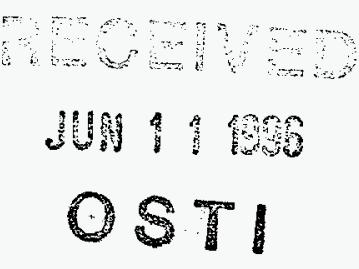

Author(s):

J. A. Oertel, P-24

C. G. Peterson, P-23

Submitted to:

11th High Tempature Plasma Diagnostics Conference. Montery, CA

May 13-17, 1996

Also to be published in Review of Scientific Instruments.

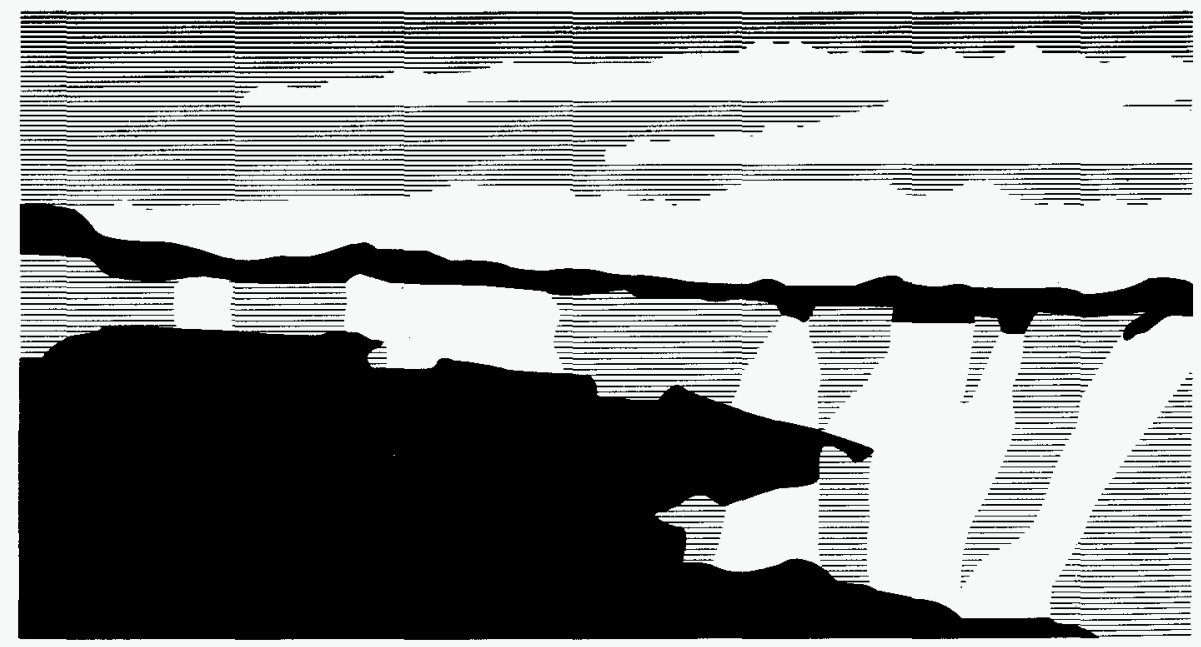

Los Alamos National Laboratory, an affirmative action/equal opportunity employer, is operated by the University of California for the U.S. Department of Energy under contract W-7405-ENG-36. By acceptance of this article, the publisher recognizes that the U.S. Government retains a nonexclusive, royalty-free license to publish or reproduce the published form of this contribution, or to allow others to do so, for U.S. Government purposes. The Los Alamos National Laboratory requests that the publisher identify this article as work performed under the auspices of the U.S. Department of Energy. 


\title{
Los Alamos Pinhole Camera (LAPC): A new flexible x-ray pinhole camera.
}

\author{
J. A. Oertel and C. G. Peterson \\ Los Alamos National Laboratory, Los Alamos, New Mexico 87545
}

We have recently designed, built and fielded a versatile, multi-channel $\mathrm{x}$-ray pinhole camera. The LAPC was designed to fit into any six inch manipulator (SIM) which is a standardized target chamber diagnostic tube. There are currently compatible SIMs available at the Trident, Omega, and NOVA laser systems. The camera uses 9 pinholes in a $3 \times 3$ array to produce images at the film plane. The film housing is designed to hold multiple sheets of stacked $x$-ray film which also uses a dark-slide to protect the film before exposure. Magnifications of 12, 8, 4 and $2 \mathrm{X}$ are selected by slipon nosecones, which support pinholes, collimators, and blast shields. Individual channel filtering is provided by a $3 \times 3$ filterpack containing 9 separate filter sub-packs. Spatial resolution is limited by the pinhole diffraction limit and field of view is dependent on magnification and filterpack diameter.

\section{INTRODUCTION}

Imaging $\mathrm{x}$-rays with pinholes has long been the diagnostic method of choice in the Inertial Confinement Fusion program (ICF) ${ }^{1,2}$ X-ray pinhole cameras are imaging devices capable of providing twodimentional views of laser heated targets. Utilizing foil filtration to select $\mathrm{x}$-ray energies per individual channels provides valuable information on target symmetry, laser pointing and other implosion dynamics. Typical shot cycles for ICF laser facilities can be less than one hour. It is important that the diagnostics be "operationally friendly" so that the shot rate is not limited by diagnostics and that instruments are easy to configure for last minute changes. We introduce a new time integrated pinhole camera that is an "operationally friendly", nine channel x-ray imager, designed to insert into any six inch manipulator (SIM). SIM's are re-enterent diagnostic tubes, compatible with Los Alamos National Laboratory's Trident ${ }^{3}$, University of Rochester's Omega ${ }^{4}$, and Lawrence Livermore National Laboratory's NOVA ${ }^{5}$ laser systems. The Los Alamos Pinhole Camera (LAPC) is designed around and interchangeable with, the standard front-end of a Gated X-ray Imager (GXI). ${ }^{6,7}$ Figure 1 shows a picture of LAPC with several magnification and filter attachments.

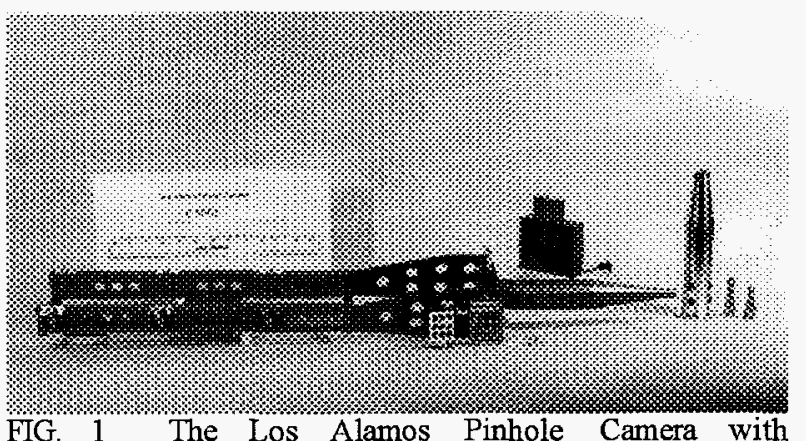

magnification and filter attachments.

\section{INSTRUMENT DESCRIPTION}

The LAPC images $x$-rays with laser drilled or wire plunge EDM constructed, 5 to $10 \mu \mathrm{m}$ diameter, pinholes. The pinholes are arranged in a (3x3) nine channel pinhole array and constructed of Tantalum to attenuate out unwanted hard $\mathrm{x}$-rays in the area outside the pinholes. Pinhole arrays typically have thickness to pinhole diameter aspect ratios of 5:1. To further reject hard $\mathrm{x}$-rays and improve signal to noise ratios a 750 $\mu \mathrm{m}$ thick Tantalum collimator with matched $250 \mu \mathrm{m}$ holes, is located behind the pinhole array. The pinhole array is protected from target debris by a blast shield made of 0.02 " Beryllium and is replaced on each shot. The film plane to object distance is fixed at $15^{\prime \prime}$ and magnification is varied by moving the position of the pinhole array relative to the object plane. Magnification snouts of $12 \mathrm{X}$ and $8 \mathrm{X}$ are selected by sliding the snouts over the end of a fixed $4 \mathrm{X}$ nosecone and $2 \mathrm{X}$ magnification is selected by a separate nosecone. A slip-in filterpack with a $3 \times 3$ filter array is located near the image plane where the images are separated by $11.6 \mathrm{~mm}$. Figure 2 shows a disassembled filterpack with one of the nine sub-packs placed off to the side. A sub-pack breaks into two halves to sandwich a sheet of filter material. Once a sub-pack is assembled it should never have to be replaced, allowing an experimenter to calibrate a specific filter. The filterpack was designed to give experimenter's flexibility in filtering each of the nine channels differently allowing views of nine different $x$ ray energies of the same image simultaneously. Experimenters have the versatility of quickly changing filterpacks and magnification snouts between shots with no effect on laser shot rate. The filmpack shown in figure 3 is made up of a filmpack body, dark-slide, loading door, and retaining pins. Five separate sheets of round x-ray film can be loaded into the filmpack allowing for a bracketed exposure for each of the nine channels. This feature is useful if the predicted x-ray flux is uncertain. X-ray film is loaded in a darkroom 
with the dark-slide closed and film door secured on top of the film stacks. The LAPC is usually prepared for a shot on a bench where the filmpack, magnification snout, pinhole array, and filterpack are loaded. The instrument is then loaded into a SIM and the dark-slide is removed. The camera travels into the target chamber inside the SIM and is aligned with an opposing port telescope.

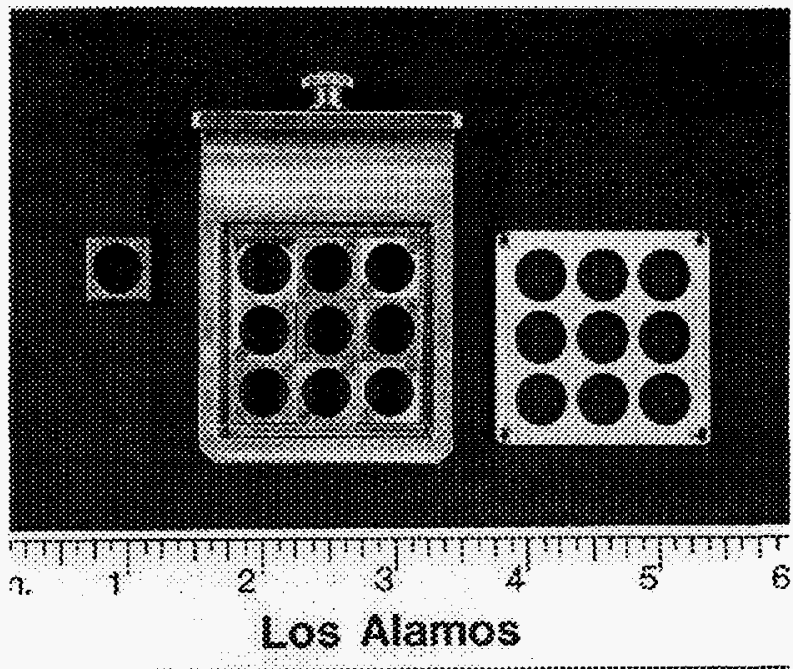

FIG. 2 Filterpack for the Los Alamos Pinhole Camera.

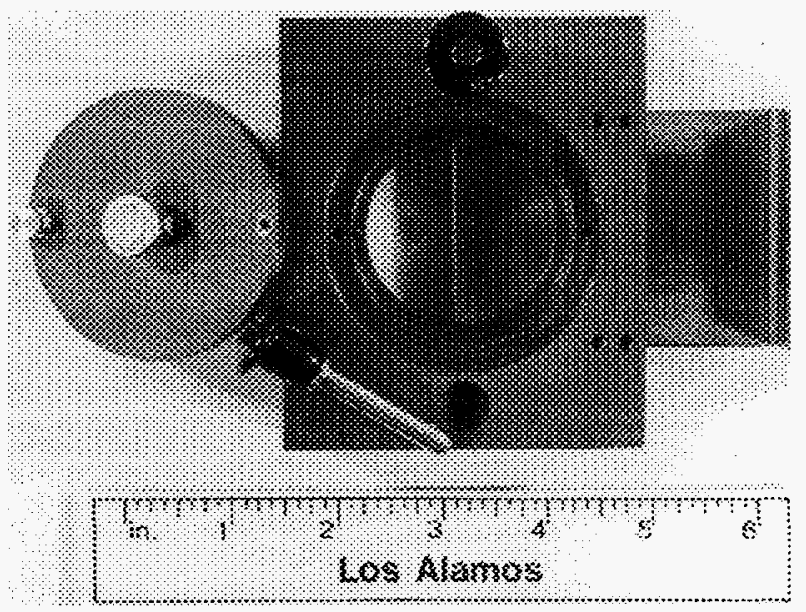

FIG. 3 Filmpack for the Los Alamos Pinhole Camera.

\section{SPATIAL RESOLUTION AND FTELD OF VIEW}

Before this camera could be sent to a remote facility, we qualified the spatial resolution with test shots at the Trident laser facility. A wire screen with wire diameters of $7 \mu \mathrm{m}$ and spacings of $25 \mu \mathrm{m}$ was backlit by $\mathrm{x}$-ray radiation from a Gold disk. The Gold disk was illuminated with a single beam of $2 \omega \mathrm{Nd}$ : Glass laser light with $1 \mathrm{~ns}$ duration, $50 \mathrm{~J}$, and $150 \mu \mathrm{m}$ spot size. Figure 4 shows an example exposure of a backlit grid at $12 \mathrm{X}$ magnification with $\mathrm{CX}$ film. The camera easily resolves the $7 \mu \mathrm{m}$ wire and diffraction theory predicts resolutions $<5 \mu \mathrm{m}$ are possible with 5 $\mu \mathrm{m}$ pinholes. ${ }^{8}$ The circular field of view is limited by the $9.54 \mathrm{~mm}$ hole diameter in the filter sub-pack. Field of views at the object plane for $12 \mathrm{X}$ is $795 \mu \mathrm{m}$, for $8 \mathrm{X}$ is $1193 \mu \mathrm{m}$, for $4 \mathrm{X}$ is $2385 \mu \mathrm{m}$, and for $2 \mathrm{X}$ is $4770 \mu \mathrm{m}$.

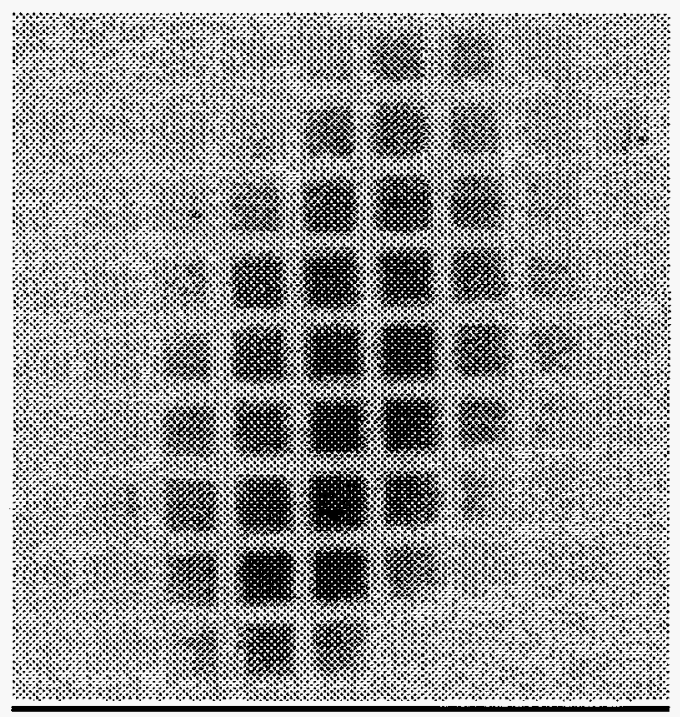

FIG. 4 Backlit grid taken at LANL's Trident laser system. Wire diameters of $7 \mu \mathrm{m}$ and spacings are 25 $\mu \mathrm{m}$ apart. LAPC was using a $12 \mathrm{X}$ magnification with CX film.

\section{CONCLUSIONS}

The LAPC has been tested on the Trident laser system and implemented on the NOVA laser system. The $\mathrm{x}$-ray pinhole camera is considered operationally friendly in that it is easy to set up and flexible in configuration. Spatial resolution is limited by diffraction effects with parameters of pinhole diameter, wavelength, distance to object, and magnification. This diagnostic is now in daily usage at the NOVA laser facility and is compatible with Trident and Omega laser facilities.

\section{ACKNOWLEDGMENTS}

The authors would like to express our appreciation for the support of the LANL P-24 diagnostic development team, the Trident laser and the NOVA laser operation crews. This work was supported by the U.S. DOE under contract W7405ENG-36. 


\section{REFERENCES}

${ }^{1}$ G.E. McCall, "X-ray Imaging in the Laser Fusion Program," SPIE Proc. in X-ray Imaging '77, Vol. 106, (1977).

${ }^{2}$ A.A.Hauer, "Design of X-ray Instrumentation for the Zeta Six Beam laser System," University of Rochester, Laboratory for Laser Energetics Annual Report, 1977.

${ }^{3}$ Information on the Trident laser system can be found at http://harry.lanl.gov/PlasmaPhysics/trident.html.

${ }^{4}$ Information on the Omega laser system can be found at http://www.lle.rochester.edu/.

${ }^{5}$ Information on the NOVA laser system can be found at http://www-lasers.llnl.gov/lasers/target.html.

${ }^{6}$ J.A. Oertel, T. Archuleta, S. Evans, J. Jimerson, T. Sedillo, R.G. Watt, "Gated X-ray Images of NOVA Hohlraums," Defense Research Review Journal, Vol 6 Number 1\&2 Jan-July 1994 UCRL\#53880-6-1\&2.

${ }^{7}$ O.L. Landen, P.M. Bell, J.A. Oertel, J.J. Satariano, and D.K. Bradley, Gain Uniformity, saturation, and depletion in micro-channel plate $x$-ray framing cameras, SPIE Proc. in Ultra High- and high speed Photography, Videography, and Photonics '93, Vol. 2002, (1993).

8 G.O Reynolds and J.H. Ward, "Coherence Theory Solution to the Pinhole Camera," J. SPIE(1), 3-8, (October/November 1966).

\section{DISCLAIMER}

This report was prepared as an account of work sponsored by an agency of the United States Ther any a their Government. Neither the United States Government or assumes any legal liability or responsibility for the accuracy, completeness, or usefulness of any information, apparatus, product, or

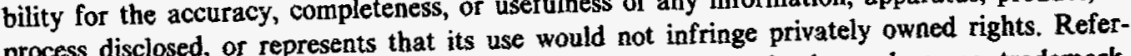
process disclosed, or representerial product, process, or service by trade name, trademark, ence herein to any specific does not necessarily constitute or imply its endorsement, recommanufacturer, or orherwise do views mendation, or favoring by the United States not necessarily state or reflect those of the and opinions of authors expressed herein do not 